\title{
Microbiology of gastrostomy site wound infections in children
}

\section{BROOK}

Department of Pediatrics, Georgetown University School of Medicine, Washington, DC, USA

\begin{abstract}
Summary. Specimens of pus were obtained from gastrostomy site wound infections in 22 children. Polymicrobial flora was found in 21 of the 22 wounds. Aerobic or facultative bacteria only were isolated in eight ( $36 \%$ ) instances and mixed aerobic-anaerobic flora were isolated from the other $14(64 \%)$ wounds. A total of 102 bacterial isolates (57 aerobic and 45 anaerobic) and seven cultures of candida were obtained. The most frequent isolates were Escherichia coli (16 isolates), Peptostreptococcus spp. (14), Enterococcus spp. (14), Bacteroides spp. (12) and Staphylococcus aureus (6). Twenty-eight strains producing $\beta$-lactamase were isolated from $16(73 \%)$ patients. The presence of polymicrobial aerobic-anaerobic infection, and the isolation of $E$. coli and Bacteroides spp. were more frequent in wounds with gastric leakage than in wounds without gastric leakage $(p<0.05)$. Bacteria similar to those isolated from the wound were also isolated from blood cultures from three patients-two isolates of $E$. coli and one each of $B$. fragilis and $S$. aureus. All patients received local therapy and 11 were treated with systemic antimicrobial agents. The polymicrobial aerobic-anaerobic flora of gastrostomy site wound infections, especially in association with gastric leakage, and the presence of $\beta$-lactamase producers in most of these infections may have important implications for their management.
\end{abstract}

\section{Introduction}

Wound infection of the gastrostomy site occurs frequently with prolonged used of a feeding gastrostomy tube. It may complicate the course of patients who require gastrostomy, making the use of gastrostomy more difficult, and leading to serious local and systemic infections. ${ }^{1,2}$ Children who require gastrostomy are often malnourished and have other medical problems that make them more susceptible to serious infections. Furthermore, because they are often hospitalised for prolonged periods, they are exposed to nosocomial pathogens and receive repeated courses of antimicrobial therapy.

There are limited studies, of the aerobic bacteriology only, of acute post-surgical gastrostomy site wound infections in adults, ${ }^{3,4}$ but the microbiology of gastrostomy site wound infections has not been studied before in children.

In this study, the aerobic and anaerobic flora of gastrostomy site wound infections in children who required a feeding gastrostomy tube for prolonged periods ( $>2$ months) were investigated. Knowledge of the bacterial flora of these wounds can assist in the proper selection of antimicrobial agents for local or systemic therapy.

\section{Patients and methods}

Clinical and microbiological data of 22 patients ( 12 male and 10 female) were evaluated. Their ages were 2-16 years (average 7.5 years). They were hospitalised between June 1976 and September 1992 at Fairview State Hospital (Costa Mesa, CA, USA) or Hospital for Sick Children (Washington, DC, USA). These children suffered from severe brain damage due to congenital or acquired neurological disorders. They required gastrostomy because of feeding difficulties for prolonged periods ( 2 months -3 years; average 10 months). None received systemic or local antimicrobial therapy before the collection of specimens.

An infected wound was defined as an area of induration and redness with exudate in and around the gastrostomy site. Cultures were obtained from the infected site by dipping a swab into the pus in the middle of the wound. The swabs were transported to the microbiology laboratory in an anaerobic transport tube (Port-A-Cul; Becton Dickson Company, Cockeysville, MD, USA) within $1 \mathrm{~h}$ of collection. 
They were cultured on blood agar and chocolate agar (incubated in $\mathrm{CO}_{2} 5 \%$ in air), and MacConkey agar (incubated in air) for aerobic bacteria. For anaerobic bacteria, vitamin $\mathrm{K} 1$-enriched brucella blood agar and selective blood agar containing kanamycin and vancomycin were used ; ${ }^{5}$ the plates were incubated immediately in anaerobic GasPak jars (BBL, Cockeysville, MD, USA). The aerobic plates were examined after 24 and $48 \mathrm{~h}$. The GasPak jars were not opened until after unbroken incubation for $48 \mathrm{~h}$ and were held for a total of 7 days. A thioglycollate broth culture was incubated anaerobically for 14 days. Aerobic and anaerobic isolates were identified by standard criteria. ${ }^{5,6}$

$\beta$-Lactamase activity was determined in all isolates with the chromogenic cephalosporin analogue $83 / 312 .{ }^{7}$ Statistical analysis was by the $\chi^{2}$ test. Cultures of blood for aerobic and anaerobic bacteria were done in 13 patients. Systemic antimicrobial therapy was given to four patients before blood-sample collection. This included two patients who received dicloxacillin and two who received erythromycin.

\section{Results}

Of the 22 wound specimens, $13(59 \%)$ were obtained from wounds that had leakage of gastric contents and $9(41 \%)$ from wounds without leakage. There were no

Table. Micro-organisms isolated from 22 gastrostomy wounds

\begin{tabular}{|c|c|c|c|}
\hline \multirow[b]{2}{*}{ Species } & \multicolumn{2}{|c|}{ Gastric leakage } & \multirow[b]{2}{*}{ Total } \\
\hline & $\begin{array}{c}\text { Present } \\
(n=13)\end{array}$ & $\begin{array}{l}\text { Absent } \\
(n=9)\end{array}$ & \\
\hline$\alpha$-Haemolytic streptococci & - & 2 & 2 \\
\hline Enterococcus spp. & 8 & 6 & 14 \\
\hline S. aureus & 2 & 4 & 6 \\
\hline S. epidermidis & 2 & 5 & 7 \\
\hline E. coli & $13^{*}$ & 3 & 16 \\
\hline$K$. pneumoniae & 1 & 3 & 4 \\
\hline Proteus spp. & 1 & 1 & 2 \\
\hline P. mirabilis & - & 1 & 1 \\
\hline Enterobacter spp. & 2 & - & 2 \\
\hline Serratia marcescens & - & 3 & 3 \\
\hline Subtotal & 29 & 28 & 57 \\
\hline \multicolumn{4}{|l|}{ Anaerobic organisms } \\
\hline Peptostreptococcus spp. & 10 & 4 & 14 \\
\hline Veillonella spp. & 2 & 一 & 2 \\
\hline Eubacterium spp. & 1 & 1 & 2 \\
\hline Fusobacterium nucleatum & 3 & 1 & 4 \\
\hline Bacteroides spp. & 1 & 1 & 2 \\
\hline B. fragilis group & 11 & 1 & 12 \\
\hline Prevotella melaninogenica & 1 & 1 & 2 \\
\hline P. intermedia & 2 & 1 & 3 \\
\hline Porphyromonas asaccharolytica & 3 & 1 & 4 \\
\hline Subtotal & $34^{*}$ & 11 & 45 \\
\hline \multicolumn{4}{|l|}{ Candida spp. } \\
\hline C. albicans & 1 & 3 & 4 \\
\hline C. tropicalis & 2 & 1 & 3 \\
\hline Subtotal & 3 & 4 & 7 \\
\hline Total & 66 & 43 & 109 \\
\hline
\end{tabular}

* Statistical difference between wounds with or without gastric leakage $(\mathrm{p}<0.05)$ differences between the ages, the length of tube placement, sex and other medical problems in the two groups. Micro-organisms were isolated from all 22 wound specimens. Polymicrobial flora was found in 21 of the 22 wounds; the number of isolates varied from two to nine isolates. A single isolate (Staphylococcus aureus) was isolated in pure culture in one instance. Aerobic bacteria only were cultured from eight $(36 \%)$ specimens, six of them from wounds without gastric leakage. Mixed aerobic and anaerobic flora was isolated from the other $14(64 \%)$ wounds, including 11 of the 13 with gastric leakage. No correlation was found between the length of tube placement and the type of organisms isolated.

There were 102 bacterial and seven candida isolates (table) (average 4.6 bacterial, and 0.3 candida isolates/ specimen); 57 of the bacterial isolates were aerobic or facultative $(2 \cdot 6 /$ specimen $)$, and 45 were anaerobic ( $2 \cdot 0 /$ specimen). The most frequent aerobic organisms were Escherichia coli (16 isolates), Enterococcus spp. (14) and S. aureus (6). The most prevalent anaerobic isolates were Peptostreptococcus spp. (14 isolates) and Bacteroides spp. (12: B. fragilis, 8; B. thetaiotaomicron, $2 ; B$. vulgatus, $1 ; B$. distasonis, 1$). E$. coli and Bacteroides spp. and anaerobic bacteria as a group were isolated more frequently from wounds with gastric leakage $(\mathrm{p}<0.05)$.

$\beta$-Lactamase activity was detected in 28 isolates from $16(73 \%)$ wounds. These included all six isolates of $S$. aureus and 12 Bacteroides isolates, three of the 16 $E$. coli isolates, two of seven $S$. epidermidis, one of four Klebsiella pneumoniae and four of nine pigmented Prevotella and Porphyromonas spp.

Blood cultures from three patients showed bacterial growth, one with $E$. coli alone, one with $E$. coli and $B$. fragilis, and one with $S$. aureus. Similar bacteria were isolated from the gastrostomy wounds of these patients.

Foul-smelling exudate was noted in 15 of these wounds, from 13 of which anaerobic organisms were isolated $(p<0.05)$. Elevated white blood count ( $>$ 12000 cells $/ \mathrm{ml}$ ) was noted in 14 of the 16 whose white blood cell count was performed. Fever $\left(>38 \cdot 2^{\circ} \mathrm{C}\right)$ was noted in 10 patients. However, other infectious problems that could have accounted for the fever were observed in five (three had bacterial tracheitis and pneumonia, and two had otitis media).

Topical wound care was given to all patients; it included wet soaks and application of neomycin, bacitracin or mycostatin preparations. It was helpful and was given on a continuous basis in most cases. Eleven patients received systemic antimicrobial therapy after specimens were collected; in six, the therapy was given because of the severity of the wound infection. The choice of antimicrobial agents was based on the wound and blood cultures. The agents used were clindamycin plus gentamicin in 10 cases, and ticarcillin plus gentamicin in one case. Response to systemic therapy of 5-10 days was generally good, with significant reduction in induration, redness and 
exudate in all 11 patients. However, recurrence of infection often occurred.

\section{Discussion}

This study demonstrated the polymicrobial aerobicanaerobic flora of gastrostomy site wound infections in neurologically impaired children hospitalised in a chronic care facility. Whether or not similar organisms can be isolated from patients with other medical problems and from those who require a gastrostomy tube for a short duration is yet to be determined. Anaerobic bacteria were especially common in wounds with gastric leakage. Their predominance in these sites may be due to the chemical effect on the wound of the gastric acid contents, the presence of the gastric tube (a foreign body) and their direct inoculation into the wound with other enteric species that colonise the stomach. Although the normal gastric contents of healthy individuals generally contain small numbers of enteric aerobic and anaerobic organisms, ${ }^{8}$ their numbers increase in individuals with gastric hypoactivity and other gastric disturbances. ${ }^{9,10}$ Although an alternative route of seeding enteric organisms may be through faecal soiling of the wound, the presence of Bacteroides spp., E. coli and Enterococcus spp. may be attributed to gastric contamination. The isolation of anaerobes of oral origin, such as Fusobacterium spp., and pigmented Prevotella and Porphyromonas spp. can be attributed to either seeding of the wound by gastric secretion which may contain these swallowed organisms or to direct inoculation of the wound by oral secretions.

The relationship between many of these aerobic and anaerobic organisms has been shown to be synergic, ${ }^{11}$

\section{References}

1. Haws EB, Sieber WK, Kiesewetter WB. Complications of tube gastrostomy in infants and children, 15-year review of 240 cases. Ann Surg 1966; 164: 284-290.

2. Gallagher MW, Tyson KRT, Ashcraft KW. Gastrostomy in pediatric patients: an analysis of complications and techniques. Surgery 1973; 74: 536-539.

3. Jonas SK, Neimark S, Panwalker AP. Effect of antibiotic prophylaxis in percutaneous endoscopic gastrostomy. $\mathrm{Am}$ $J$ Gastroenterol 1985; 80: 438-441.

4. Jain NK, Larson DE, Shroeder KW et al. Antibiotic prophylaxis for percutaneous endoscopic gastrostomy. A prospective, randomized, double-blind clinical trial. Ann Intern Med 1987; 107: 824-828.

5. Sutter VL, Citron DM, Finegold SM. Wadsworth Anaerobic bacteriology manual, 4 th edn. Belmont, California, Star Publishing Co. 1985.

6. Lennette EH, Balows A, Hausler WJ, Shadomy H-J. Manual of clinical microbiology, 4th edn. Washington, DC, American Society for Microbiology. 1985

7. O'Callaghan CH, Morris A, Kirby SM, Shingler AH. Novel method for detection of beta-lactamase by using a chromogenic cephalosporin substrate. Antimicrob Agents Chemother 1972; 1: 283-288.

8. Gorbach SL. Intestinal microflora. Gastroenterology $1971 ; 60$ : 1110-1129. which may make them more virulent and more difficult to eradicate. Also, the presence of $\beta$-lactamase-producing bacteria (BLPB) in over two-thirds of gastrostomy site wounds may have important implications for the choice of antimicrobial agents for the management of these wound infections. BLPB may "protect" other micro-organisms that are susceptible to penicillin from the activity of that drug $;^{12}$ this ability has been demonstrated in vitro ${ }^{13}$ and in vivo. ${ }^{14}$ BLPB can emerge rapidly in patients who receive penicillin therapy. ${ }^{15}$ Furthermore, such organisms are prevalent in the hospital environment, especially in individuals who have received multiple courses of $\beta$ lactam antibiotics. ${ }^{16}$ Although local wound care is generally adequate when there is local or systemic spread of infection, the administration of antimicrobial agents effective against aerobic and anaerobic BLPB should be considered.

Because anaerobic bacteria and enterobacteria are frequently associated with gastrostomy site wounds in paediatric patients, especially in wounds that are associated with gastric leakage, their presence should be anticipated if systemic antimicrobial therapy is used. ${ }^{17}$ Gram's staining of the exudate and appropriate aerobic and anaerobic techniques in cultivating specimens can help in identifying the wound's bacterial flora and selecting the proper therapy. Topical wound care is the management of choice of most wounds. However, the administration of systemic antimicrobial agents may be indicated in selected cases, especially when bacteraemia occurs. This could also be important in the event of poor response to local therapy and sometimes spread of the infection.

The laboratory support of D. Citron, S. Bartlett, L. Calhoun and P. Yocum and the secretarial assistance of S. Blaisdell are gratefully acknowledged.

9. King CE, Toskes PP. Small intestine bacterial overgrowth. Gastroenterology 1979; 76: 1035-1055.

10. Giannella RA, Broitman SA, Zamcheck N. Influence of gastric acidity on bacterial and parasitic infections. A perspective. Ann intern Med 1973; 78 : 271-276.

11. Brook I, Hunter V, Walker RI. Synergistic effect of Bacteroides, Clostridium, Fusobacterium, anaerobic cocci and aerobic bacteria on mortality and induction of subcutaneous abscesses in mice. $J$ Infect Dis 1984; 149: 924-928

12. Brook I. The role of beta-lactamase-producing bacteria in the persistence of streptococcal tonsillar infection. Rev Infect Dis 1984; 6: 601-607.

13. Brook I, Pazzaglia G, Coolbaugh JC, Walker RI. In vivo protection of group A beta-haemolytic streptococci from penicillin by beta-lactamase-producing Bacteroides species. $J$ Antimicrob Chemother-Microbiol 1983; 12 : 599-606.

14. Brook I, Yocum P. In vitro protection of Group A betahemolytic streptococci from penicillin and cephalothin by Bacteroides fragilis. Chemotherapy 1983; 29: 18-23.

15. Brook I, Gober AE. Emergence of beta-lactamase-producing aerobic and anaerobic bacteria in the oropharynx of children following penicillin chemotherapy. Clin Pediatr 1984; 23 : 338-341.

16. Brook I, Calhoun L, Yocum P. Beta-lactamase-producing isolates of Bacteroides species from children. Antimicrob Agents Chemother 1980; 18: 164-166.

17. Finegold SM. Anaerobic bacteria in human disease. New York, Academic Press Inc. 1977 